\title{
CONCAVITY OF THE ERROR FUNCTION WITH RESPECT TO HÖLDER MEANS
}

\author{
YUMING CHU AND TIEHONG ZHAO
}

Abstract. In this paper, we present a necessary and sufficient condition for the concavity of the error function with respect to Hölder means.

Mathematics subject classification (2010): 33B20, 26E60.

Keywords and phrases: Error function, concavity, Hölder mean.

\section{REFERENCES}

[1] H. Alzer, Functional inequalities for the error function, Aequationes Math. 66, 1-2 (2003), 119127.

[2] H. Alzer, Functional inequalities for the error function II, Aequationes Math. 78, 1-2 (2009), 113121.

[3] H. Alzer, Error function inequalities, Adv. Comput. Math. 33, 3 (2010), 349-379.

[4] G. D. Anderson, M. K. Vamanamurthy And M. Vuorinen, Conformal Invariants, Inequalities, and Quasiconformal Maps, John Wiley \& Sons, New York, 1997.

[5] G. D. Anderson, M. K. Vamanamurthy and M. Vuorinen, Generalized convexity and inequalities, J. Math. Anal. Appl. 335, 2 (2007), 1294-1308.

[6] Á. BARICZ, Convexity of the zero-balanced Gaussian hypergeometric functions with respect to Hölder means, JIPAM. J. Inequal. Pure Appl. Math. 8, 2 (2007), Article 40, 9 pages.

[7] Á. BARICZ, Geometrically concave univariate distributions, J. Math. Anal. Appl. 363, 1 (2010), 182 196.

[8] Á. BARICZ, A functional inequality for the survival function of the gamma distribution, JIPAM. J. Inequal. Pure Appl. Math. 9, 1 (2008), Article 13, 5 pages.

[9] R. K. Bhaduri And B. K. Jennings, Note on the error function, Amer. J. Phys. 44, 6 (1976), 590-592.

[10] B. A. BHAYO AND M. VUORINEN, Power mean inequality of generalized trigonometric function, arixv: 1209.0873 [math. CA], available online at http://arxiv.org/pdf/1209.0873v1.pdf.

[11] D. Borwein, J. Borwein, G. Fee And R. Girgensohn, Refined convexity and special cases of the Blaschke-Santalo inequality, Math. Inequal. Appl. 4, 4 (2001), 631-638.

[12] P. S. Bullen, Handbook of Means and Their Inequalities, Kluwer Academic Publishers Group, Dordrecht, 2003.

[13] J. T. CHU, On bounds for the normal integral, Biometrika, 42, (1985), 263-265.

[14] Y.-M. ChU, M.-K. WANG, Y.-P. JIANG AND S.-L. QIU, Concavity of the complete elliptic integrals of the second kind with respected to Hölder means, J. Math. Anal. Appl. 395, 2 (2012), 637-642.

[15] A. LAFORGIA AND S. SISMONDI, Monotonicity results and inequalities for the gamma and error functions, J. Comput. Appl. Math. 23, 1 (1988), 25-33.

[16] J. MatKows KI AND J. RÄTZ, Convexity of power functions with respect to symmetric homogeneous means, in: General Inequalities 7 (Oberwolfach, 1995), Internat. Ser. Numer. Math., 123 (1997), Birkhäuser, Basel, 231-247.

[17] J. Matkowski And J. RÄTZ, Convex functions with respect to an arbitrary mean, in: General Inequalities 7 (Oberwolfach, 1995), 123 (1997), Birkhäuser, Basel, 249-258.

[18] D. S. Mitrinović And R. J. Weinacht, Solutions of advanced problems: 5555, Amer. Math. Monthly, 75, 10 (1968), 1129-1130. 
[19] G.-D. WANG, X.-H. Zhang And Y.-P. JIANG, Concavity with respect to Hölder means involving the generalized Grötzsch function, J. Math. Anal. Appl. 379, 1 (2011), 200-204.

[20] M.-K. WANG, Y.-M. CHU, S.-L. QIU AND Y.-P. JiAnG, Convexity of the complete elliptic integrals of the first kind with respected to Hölder means, J. Math. Anal. Appl. 388, 2 (2012), 1141-1146.

[21] X.-H. ZHANG, G.-D. WANG AND Y.-M. CHU, Convexity with respect to Höder mean involving zero-balanced hypergeometric functions, J. Math. Anal. Appl. 353, 1 (2009), 256-259.

[22] L.-M.ZHOU, S.-L. QIU AND F. WANG, Inequalities for the generalized elliptic integrals with respect to Hölder means, J. Math. Anal. Appl. 386, 2 (2012), 641-646. 